\title{
Assessment of the Accuracy of Estimation of Blood Loss by Health Care Professionals in Federal Medical Centre Assessment Owerri, Nigeria
}

\author{
E. A. Nzeribe1, O. A. Onyegbule1", E. E. Idih¹, C. M. Anyaeze², D. Chukwumam³ \\ ${ }^{1}$ Department of Obstetrics and Gynecology, Federal Medical Centre, Owerri, Nigeria \\ ${ }^{2}$ Department of Surgery, Federal Medical Centre, Owerri, Nigeria \\ ${ }^{3}$ Department of Trauma and Orthopedics, Federal Medical Centre, Owerri, Nigeria \\ Email: *onyemath1@gmail.com
}

How to cite this paper: Nzeribe, E.A., Onyegbule, O.A., Idih, E.E., Anyaeze, C.M. and Chukwumam, D. (2019) Assessment of the Accuracy of Estimation of Blood Loss by Health Care Professionals in Federal Medical Centre Assessment Owerri, Nigeria. Open Journal of Obstetrics and Gynecology, 9, 83-91.

https://doi.org/10.4236/ojog.2019.91009

Received: November 20, 2018

Accepted: January 15, 2019

Published: January 18, 2019

Copyright $\odot 2019$ by author(s) and Scientific Research Publishing Inc. This work is licensed under the Creative Commons Attribution International License (CC BY 4.0).

http://creativecommons.org/licenses/by/4.0/

\section{(c) (i) Open Access}

\begin{abstract}
Background: Visually estimated blood loss has long been known to be imprecise, inaccurate, and often underestimated, which may lead to delayed diagnosis and treatment. Aim: To determine the accuracy of blood estimates by health workers in surgical and obstetric specialties. Methodology: This was a cross sectional single blinded observational study done in January 2016 to determine discrepancy between actual blood loss (ABL) and estimated blood loss (EBL) by consenting healthcare practitioners working in various surgical and obstetric departments of the Federal Medical centre, Owerri. Reconstituted whole blood was obtained from the blood bank, and simulated scenarios with known measured blood loss were created using common surgical materials. Visually estimated blood loss was performed by medical personnel. Percent errors of estimated blood loss were calculated and comparisons were made among the health professionals. The statistical analysis was done using SPSS version 21. Results: A total of 113 health professionals comprising 64 doctors and 49 nurses assessed 7 clinical scenarios. On the average, there was a general tendency for the health workers to under estimate the volume. Majority of the participants underestimated the blood volume by more than $20 \%$ of actual volume. Though the nurses were more likely to underestimate blood volume than the doctors however, there was no statistical difference between the estimations by the nurses and the doctors except in station 3 with a p value of 0.045. Conclusion: This finding calls for action in training and retraining of every health worker in blood loss estimation, so that intervention can be initiated early.
\end{abstract}




\section{Keywords}

Accuracy, Blood loss, Health Care Professionals, Owerri

\section{Introduction}

Excessive blood loss during childbirth, traffic accidents, war time injury, and surgery with the resultant morbidity and mortality is a problem that has occurred throughout history. Post partum hemorrhage accounts for about a quarter of maternal mortality and remains the major cause of death especially in resource poor areas. Delayed and substandard obstetrics care can kill a woman within hours of Major Obstetric Haemorrhage [1].

Over the years attempts to reduce the contribution of this preventable cause of mortality and morbidity by way of risk assessment, taking of necessary precautions and active management of third stage of labor have been done. Obstetric care has changed in an attempt to decrease blood loss, yet postpartum hemorrhage $(\mathrm{PPH})$ still alarms birth attendants because of the rapidity of its onset and danger it represents if uncontrolled [2]. Traumatic injuries from traffic accidents, combat missiles, assault, major surgical operations, etc. may also cause massive blood loss especially when large vessels are involved.

The importance of accurate estimation of blood loss, prompt recognition and treatment of clotting disorders, early involvement of a haematologist and anaesthetist in resuscitation, use of adequately sized intravenous cannulae and precise monitoring of central venous pressure have all been advocated [3].

In clinical practice, the amount of blood lost is estimated by different members of the medical team. Typically in Obstetrics and Gynaecology by the birth attendant while in Surgical sub specialties by the surgeons, anaesthetists and perioperative nurses. Even with repetitive studies identifying the limitations and inaccuracies of estimation, visual method is the easiest and most common method of quickly gauging blood loss [4] [5].

Other methods of blood loss estimation include use of Kelly's pad (India); kangas (Tanzania) blood drape (Nigeria); gravimetric method, alkaline hematin method/Acid hematin method [6]. Most of these are sponsored by Nongovernmental organizations and are not available regularly in our day to day clinical practice. A method of blood loss estimation such as calculation of estimated blood loss requires the use of post delivery heamatocrit for calculation. This method is therefore not useful in the prompt decision making for intervention. Formula: percent of blood volume lost equals \{pre delivery HCT - post delivery HCT\}/pre delivery HCT [7]. Spectrophotometry has been suggested as gold standard for laboratory based technique for blood loss calculation because of reported error rates of $0 \%$ to $10 \%$ [8], but will not be practicable under clinical scenario.

Accurate estimation of actual blood loss helps to forewarn the occurrence of 
hypovolaemic shock [9]. Prior studies have suggested that health professionals tend to overestimate small losses $(<150 \mathrm{ml})$ and underestimate large ones $(>150$ ml) [10] [11]. Anaesthetists were found to also over-estimate blood loss significantly more than orthopaedic and general surgeons [12]. All however had more tendency to overestimate smaller volumes than larger ones [13] [14]. Blood samples in kidney dishes and other clinical receptacles were more accurately estimated than those on drapes and cloths [15]. In clinical scenarios, vital parameters suggesting instability were associated with over estimation of small blood volumes and under estimation of larger ones [16]. Owing to the fact that discrepancies exist in the estimation of blood loss during surgery by health care professionals, therefore this study aimed at corroborating or refuting these discrepancies so that proper early intervention could be given when necessary.

\section{Methodology}

This was a cross sectional single blinded observational study to determine discrepancy between actual blood loss (ABL) and estimated blood loss (EBL) by consenting healthcare practitioners working in various surgical and obstetric departments of a tertiary hospital in Owerri the capital of Imo state in South-East geopolitical zone of Nigeria. The centre is the major health facility in the state serving as a referral center while also undertaking primary health care functions for persons in the metropolis and its environs.

This study was carried out in January 2016 and included health care professionals such as obstetricians, anesthesiologists, trauma physicians, nurses, midwives and health assistant. The approval for the study was obtained from the ethical committee of the Federal Medical Center Owerri. Permission was also obtained from the management of the labour ward, haematology, theatre and emergency units.

Consent was gotten from the subjects. The risk of exposure to blood was recognized. Only screened blood from the Haematology Laboratory was used. Universal precautions in the handling of blood products were observed. Adequate information on the potential risk implication was explained to the subjects

All the health care providers in the surgical specialties were invited to participate in the study. Information about the study was disseminated by way of notices in the different departments as well as text messages to individuals after obtaining permission from the heads of department and ethical approval. Those who came for the study which was simulated at the Obstetrics and Gynecology conference room were given general information on the importance of accurate blood loss estimation even with the visual methods. After counseling, those who consented to continue were invited to participate. The study was a needs assessment to help determine line of intervention needed to improve practice in the centre.

Clinical scenarios were reproduced in the form of Objective Structured Clinical Examination (OSCE) style stations. Expired blood from the blood bank was 
collected and used for the purposes of this study. Universal blood safety measures were taken during the conduct of this study. Different volumes of blood known only to the investigators was placed in gauze swabs, delivery/bed mat, vulval pads, abdominal packs ,mackintosh, green cloth and patient's cloth, and calibrated containers. Each health care provider took turns individually to visualize and estimate blood volume at each of the stations and write down there estimates of the blood in the different stations.

After the exercise the accurate estimates were made known to each of the research subjects to enable them make objective corrections to their estimations in future.

The materials were disposed off safely, while ensuring universal precautions in their handling to avoid infection of the researchers and others.

The statistical analysis was done using SPSS version 21 . The error margin was calculated from the difference between the actual volume and the estimated volume. The estimates were grouped into those within $20 \%$ above and below the actual volume of blood; and those less and those more than the actual volumes by over $20 \%$ respectively. Frequency tables and charts were used to represent relevant variables and observed patterns. Student t-test was used were applicable to compare means. All analysis will be done at $5 \%$ level of significance with $\mathrm{P}<$ 0.05 considered statistically significant.

\section{Results}

One hundred and thirteen health workers participated in the study, 64 of whom were doctors while 49 were nurses. On the average, there was a general tendency for the health workers to under estimate the volume. The nurses were more likely to underestimate than the doctors. They nurses underestimated more than the doctors in stations 1, 2, 5 and 6. But the mean accuracy was better in stations 3, 4 and 7 when compared with that of the doctors (Table 1). When the absolute mean accuracy (which considers errors in estimation without minding overestimation or underestimation, nurses had better absolute mean accuracy in stations 2, 4, 5, 6, and 7 (Table 1).

In Table 2, there was no statistical difference between the estimations by the nurses and the doctors except in station 3 (perineal pad) which had a p value of 0.045 .

In Table 3: Majority of the participants underestimated the blood volume by more than $20 \%$ of actual volume. Nurses generally underestimated more than the doctors however, there was $>20 \%$ underestimation of blood loss in all the stations by both the doctors and the nurses. In station 2 where there was $145 \mathrm{ml}$ of blood in kidney dish, $28.7 \%$ of doctors and $34.7 \%$ of nurses estimated blood loss within $20 \%$ of value compared to station 5 ( $120 \mathrm{ml}$ of blood in bed mat) where neither the doctors nor the nurses estimated blood loss within $20 \%$ of value. 
Table 1. Comparative analysis of accuracy of estimation between the doctors and the nurses.

\begin{tabular}{cccc}
\hline & Profession & Mean accuracy \pm SD & Absolute mean error \pm SD \\
\hline 1 & doctors & $10.67 \pm 28.69$ & $16.45 \pm 25.70$ \\
& nurses & $6.91 \pm 24.00$ & $21.86 \pm 53.31$ \\
2 & doctors & $17.5 \pm 121.42$ & $88.43 \pm 84.31$ \\
& nurses & $5.00 \pm 69.55$ & $62.24 \pm 79.97$ \\
3 & doctors & $6.8 \pm 86.11$ & $63.86 \pm 57.91$ \\
& nurses & $36.67 \pm 54.55$ & $65.24 \pm 35.10$ \\
4 & doctors & $132.89 \pm 288.71$ & $201.17 \pm 245.32$ \\
& nurses & $157.14 \pm 262.46$ & $194.69 \pm 235.37$ \\
& doctors & $102.11 \pm 237.02$ & $153.83 \pm 206.72$ \\
& nurses & $113.47 \pm 292.12$ & $146.12 \pm 276.91$ \\
& doctors & $208.41 \pm 473.86$ & $326.51 \pm 400.45$ \\
& nurses & $190.00 \pm 295.35$ & $249.18 \pm 233.81$ \\
& doctors & $32.22 \pm 123.31$ & $70.71 \pm 107.68$ \\
\hline
\end{tabular}

Table 2. Blood loss estimation by doctors and nurses.

\begin{tabular}{|c|c|c|c|c|c|c|c|c|}
\hline Station & Profession & Actual value & $\begin{array}{l}\text { Minimum } \\
\text { estimate }\end{array}$ & $\begin{array}{c}\text { Maximum } \\
\text { estimate }\end{array}$ & $\begin{array}{c}\text { Mean error } \\
\text { margin }\end{array}$ & $\begin{array}{l}\text { Standard } \\
\text { deviation }\end{array}$ & t-test & p-value \\
\hline \multirow[t]{2}{*}{ 1) Gauze swab } & $\begin{array}{l}\text { Doctors } \\
\mathrm{N}=64\end{array}$ & 15 & 4 & 150 & 10.67 & 28.69 & 0.739 & 0.462 \\
\hline & $\begin{array}{l}\text { Nurses } \\
\mathrm{N}=49\end{array}$ & 15 & 1 & 100 & 6.91 & 24.00 & & \\
\hline \multirow[t]{2}{*}{ 2) Kidney dish. } & Doctors & 145 & 15 & 600 & 17.5 & 121.42 & 0.644 & 0.521 \\
\hline & Nurses & 145 & 20 & 350 & 5.0 & 69.55 & & \\
\hline \multirow[t]{2}{*}{ 3) Perineal pad. } & doctors & 100 & 3 & 400 & 6.8 & 86.11 & 2.025 & 0.045 \\
\hline & Nurses & 100 & 8 & 300 & 36.67 & 54.55 & & \\
\hline \multirow[t]{2}{*}{ 4) Wrapper } & doctors & 180 & 25 & 1500 & 132.89 & 288.71 & -0.46 & 0.646 \\
\hline & Nurses & 180 & 20 & 1500 & 157.14 & 262.46 & & \\
\hline \multirow[t]{2}{*}{ 5) Delivery mat } & doctors & 120 & 15 & 1000 & 102.11 & 237.02 & 0.228 & 0.82 \\
\hline & Nurses & 120 & 10 & 2000 & 113.47 & 292.12 & & \\
\hline \multirow[t]{2}{*}{ 6) Green cloth } & doctors & 300 & 20 & 2000 & 208.41 & 473.86 & 0.238 & 0.812 \\
\hline & Nurses & 300 & 50 & 1000 & 190.00 & 295.35 & & \\
\hline \multirow[t]{2}{*}{ 7) Gallipot } & doctors & 85 & 10 & 800 & 32.22 & 123.31 & 0.923 & 0.358 \\
\hline & Nurses & 85 & 8 & 250 & 13.00 & 56.16 & & \\
\hline
\end{tabular}

\section{Discussion}

This was a cross sectional comparative study on the accuracy of blood loss estimation by doctors and nurses in a tertiary hospital in south east Nigeria. It is known that blood loss estimation by visual inspection is usually not accurate. However, this happens to be the readily available method of estimation since 
Table 3. Accuracy of visual estimation of blood.

\begin{tabular}{|c|c|c|c|c|c|}
\hline Stations & Profession & $\begin{array}{l}\text { Under estimation by } \\
>20 \% \text { of value (\%) }\end{array}$ & $\begin{array}{c}\text { Estimation within } 20 \% \\
\text { of value (\%) }\end{array}$ & $\begin{array}{c}\text { Overestimation } \\
\text { by }>\mathbf{2 0} \% \text { of value (\%) }\end{array}$ & Total \\
\hline \multirow[t]{2}{*}{ 1) (15 $\mathrm{ml}$ in gauze piece) } & Doctors & 46 (71.9) & $5(7.8)$ & $13(20.3)$ & 64 \\
\hline & Nurse & $37(75.5)$ & $1(2.0)$ & $11(22.4)$ & 49 \\
\hline \multirow[t]{2}{*}{ 2) (145 $\mathrm{ml}$ in kidney dish) } & Doctor & $41(64.1)$ & $19(28.7)$ & $4(6.3)$ & 64 \\
\hline & Nurse & $27(55.1)$ & $17(34.7)$ & $5(10.2)$ & 49 \\
\hline \multirow[t]{2}{*}{ 3) (100 $\mathrm{ml}$ in $\mathrm{pad})$} & Doctor & $56(87.5 \%)$ & $3(4.7)$ & $5(7.8)$ & 64 \\
\hline & Nurse & $46(93.9)$ & $2(4.1)$ & $1(2.0)$ & 49 \\
\hline \multirow[t]{2}{*}{ 4) (180 $\mathrm{ml}$ in wrapper) } & Doctor & $36(56.3)$ & $2(3.1)$ & $26(40.6)$ & 64 \\
\hline & Nurse & $36(73.5)$ & $1(2.0)$ & $12(24.5)$ & 49 \\
\hline \multirow[t]{2}{*}{ 5) (120 $\mathrm{ml}$ in bedmat) } & doctors & $56(87.5)$ & $0(0)$ & $8(12.5)$ & 64 \\
\hline & Nurse & $43(87.8)$ & $0(0)$ & $6(12.2)$ & 49 \\
\hline \multirow[t]{2}{*}{ 6) ( $300 \mathrm{ml}$ in green cloth) } & Doctor & $53(82.8)$ & $6(9.4)$ & $5(7.8)$ & 64 \\
\hline & Nurse & $44(89.8)$ & $1(2.0)$ & $4(8.2)$ & 49 \\
\hline \multirow[t]{2}{*}{ 7) (85 $\mathrm{ml}$ of blood in a gallipot) } & Doctor & $34(53.1)$ & $10(15.6)$ & $20(31.3)$ & 64 \\
\hline & Nurse & $30(61.2)$ & $6(12.2)$ & $13(26.5)$ & 49 \\
\hline
\end{tabular}

other methods like gravimetric, photometric were not routinely done and is not usually feasible in low resource settings. It became pertinent to see how the key health workers involved in the estimation of blood loss in the obstetric and surgical specialties make their estimations with the full knowledge of how this will impact on patient care. It is known that when feedback is given to the participants there will be a positive change in estimation.

The error margins were generally less for the nurses than for the doctors. When blood was placed in containers like the galipot and kidney dishes accuracy was relatively better than when blood was placed in pads, clothes and delivery mats. In the later groups the error margin was very high. This could be explained by the fact that the practitioners may have an idea of the possible volume of those containers albeit wrongly. Varying absorbency of fabric like materials like pads and perineal pads can mislead a practitioner in making estimates of blood within them. This was similar to reports by previous authors as stated earlier [14]. Further interventional study may be needed to inform the practitioners of the measurements of blood in these media. Simulation, education and evaluation have been shown to improve accuracy and will be recommended [15].

One can also venture to suggest backing up measurement of blood in such fabric like material with gravimetric methods even though such methods need timely implementation and could be labor intensive [16]. That accuracy was best for blood in containers showed that use of measurable instruments will be more useful in estimating blood loss. This can be improved when calibrated instruments like syringe, measuring cylinders etc are used to measure actual volumes by an assistant during surgeries or deliveries. The use of these containers can 
therefore be recommended for use more often, but a lot of drawbacks for this use abound. The real life scenario is such that the operating gowns, aprons, gloves, drapes and mats will definitely have blood on them and therefore merely estimating blood in containers accurately will not solve the problem. This is despite the possibility of other body fluids mixing up with the blood in real life scenario.

The bed/delivery mat is an absorbent clothing pad used to soak up blood in theatre and in the delivery room. Patients usually lie on it and it is almost always used. From this study, no doctor or nurse was able to estimate loss within $20 \%$ of the actual volume. Rather close to $90 \%$ of the doctors and nurses underestimated the blood volume by more than $20 \%$. This means that the promptness of intervention to reduce incidences of hypovolemic shock with the attendant morbidity will be poor. This finding calls for action in training and retraining of every health worker in blood loss estimation. Poor estimations were made for blood in perineal pads, delivery mats and wrappers.

In this study majority of the health care professionals tended to underestimate blood loss and this was contrary to reports from a study by Young et al in 2009 which found a tendency to overestimate blood volumes by healthcare workers [13]. Another study by Silva et al. 2014 reaffirmed suboptimal correlation between actual blood volume and visual estimate with a tendency to overestimate blood loss [17]. A need therefore arises to increase the use of clinical state of the patient to assess blood loss.

Suskerasert et al. noted that educational programs significantly increased accuracy of blood loss estimation and is therefore recommended for health professionals in this centre [18].

\section{Limitations}

As this was the pilot study done in this area in our environment, only 2 groups were considered for easy analysis and comparisons, a sub group analysis would have been better to in-cooperate all the cadres of health workers in surgical specialty. Secondly, factors which could affect the accuracy of blood estimation were not analyzed in this study, further research is important in this area so that confounding variables would be identified.

\section{Conclusion}

There was a tendency of underestimation by both doctors and nurses. Nurses were more likely to underestimate when compared to doctors. When blood was placed in containers like the galipot and kidney dishes accuracy was relatively better than when blood was placed in pads, clothes and delivery mats because varying absorbency of fabric like materials can mislead a practitioner in making estimates of blood within them. Because of the general underestimation by all health workers in this study, early intervention to prevent hypovolemoic shock might be delayed with its attendant morbidity and mortality. Therefore, this 
finding calls for action in training and retraining of every health worker in blood loss estimation.

\section{Authors' Contribution}

This work was carried out in collaboration of all authors. Authors NEA, ACM and IEE were involved in the design and writing of the protocol and the first draft. Authors NEA, OAO and CD were involved in the statistical analysis. All authors read and approved the final manuscript.

\section{Conflicts of Interest}

The authors declare no conflicts of interest regarding the publication of this paper.

\section{References}

[1] Rani, P.R. and Begum, J. (2017) Recent Advances in the Management of Major Postpartum Haemorrhage-A Review. Journal of Clinical and Diagnostic Research, 11, QE01-QE05. https://doi.org/10.7860/JCDR/2017/22659.9463

[2] Cunningham, F.G., Leveno, K.L., Bloom, S.L., et al. (2005) Williams Obstetrics. 22nd Edition, McGraw-Hill, New York.

[3] Bose, P., Regan, F. and Paterson-Brown, S. (2006) Improving the Accuracy of Estimated Blood Loss at Obstetric Haemorrhage Using Clinical Reconstructions. BJOG, 113, 919-924. https://doi.org/10.1111/j.1471-0528.2006.01018.x

[4] Hofmeyr, G.J. and Mohlala, B.K.F. (2001) Hypovolaemic Shock. Best Practice \& Research Clinical Obstetrics \& Gynaecology, 154, 645-662. https://doi.org/10.1053/beog.2001.0205

[5] Bellamy, M.C. and Ermenyi, A. (2007) Haematological Disorders and Blood Transfusion. In: Textbook of Anaesthesia, 5th Edition, Churchill Livingstone, New York, 439-443.

[6] Path Blood Loss Measurement Technology Opportunity Assessment Prepared for the Merck for Mothers Program 2013 Program for Appropriate Technology in Health (PATH).

[7] Stafford, I., Dildy, G.A., Clark, S.L. and Belfort, M.A. (2008) Visually Estimated and Calculated Blood Loss in Vaginal and Cesarean Delivery. American Journal of $O b-$ stetrics and Gynecology, 199, 519.e1-519.e7.

https://doi.org/10.1016/j.ajog.2008.04.049

[8] Hancook, A., Weeks, A.D. and Lavender, D.T. (2015) Is Accurate and Reliable Blood Loss Estimation the Crucial Step in Early Detection of Post Partum Hemorrhage: An Integrative Review of the Literature. BMC Pregnancy and Childbirth, 15, 230. https://doi.org/10.1186/s12884-015-0653-6

[9] Murphy, M.F., Wallington, T.B., Kelsy, P., Boulton, F., Bruce, M., Cohen, H., et al. (2001) Guidelines for the Clinical Use of Red Cell Transfusions. British Journal of Haematology, 113, 24-31. https://doi.org/10.1046/j.1365-2141.2001.02701.x

[10] Ekeroma, A.J., Ansari, A. and Stirrat, G.M. (1997) Blood Transfusions in Obstetrics and Gynaecology. British Journal of Obstetrics and Gynaecology, 104, 278-284. https://doi.org/10.1111/j.1471-0528.1997.tb11454.x

[11] Gabel, K.T. and Weeber, T.A. (2012) Measuring and Communicating Blood Loss 
during Obstetric Haemorrhage. Journal of Obstetric, Gynaecologic \& Neonatal Nursing, 41, 551-558. https://doi.org/10.1111/j.1552-6909.2012.01375.x

[12] Ashburn, J.C., Harrison, T., Hamm, J.J. and Strote, J. (2012) Emergency Physician Estimation of Blood Loss. Western Journal of Emergency Medicine, 13, 376. https://doi.org/10.5811/westjem.2011.9.6669

[13] Young, W., Karavolos, S., Damodaran, M., Madgwick, K., Milestone, N., AL-Habib, A., et al. (2010) Observer Accuracy and Reproducibility of Visual Estimation of Blood Loss in Obstetrics: How Accurate and Consistent Are Health Care Professionals? Archives of Gynaecology and Obstetrics, 281, 207-213. https://doi.org/10.1007/s00404-009-1099-8

[14] Meiser, A., Casagranda, O., Skipka, G. and Laubenthal, H. (2001) Quantification of Blood Loss. How Precise Is Visual Estimation and What Does Its Accuracy Depend on? Der Anaesthesist, 50, 13-20. https://doi.org/10.1007/s001010050957

[15] Dildy, G.A., Paine, A.R., George, N.C. and Velasco, C. (2004) Estimating Blood Loss: Can Teaching Significantly Improve Visual Estimation? ACOG, 104, 601-606. https://doi.org/10.1097/01.AOG.0000137873.07820.34

[16] Schorn, M.N. (2010) Measurement of Blood Loss: Review of the Literature. Journal of Midwifery \& Women's Health, 55, 20-27. https://doi.org/10.1016/j.jmwh.2009.02.014

[17] De La Peña Silva, A.J., Delgado, R.P, Barretoc, I.Y. and De La Peña Martíneza, M. (2014) Is Visual Estimation Useful in Determining the Extent of Perioperative Hemorrhage? A Study of Correlation among Anesthetists of Intermediate and High Complexity Hospitals in Cartagena, Columbia. Colombian Journal of Anesthesiology, 42, 247-254. https://doi.org/10.1016/j.rcae.2014.05.003

[18] Suskerasert, M., Choktanasiri, W., Ayudhya, N.I., Promsothi, P. and O-Prasertsawat, P. (2006) Increase Accuracy of Visual Estimation of Blood Loss from Educational Program. Journal of the Medical Association of Thailand, 89, S54-S59. 